Dokuz Eylül Üniversitesi-Mühendislik Fakültesi

Fen ve Mühendislik Dergisi

Cilt 19, Sayı 56, Mayıs 2017
Dokuz Eylul University-Faculty of Engineering Journal of Science and Engineering Volume 19, Issue 56, May 2017

DOI: $10.21205 /$ deufmd.2017195653

\title{
Simetrik Katmanlı İnce Dikdörtgen Kompozit Plakların Burkulması
}

\section{Erkin ALTUNSARAY}

Dokuz Eylül Üniversitesi, Deniz Bilimleri ve Teknolojisi Enstitüsü, Gemi İnşaatı Programı, 34340, İzmir

(Alınıș / Received: 19.12.2016, Kabul / Accepted: 21.03.2017, Online Yayınlanma / Published Online: 02.05.2017)

Anahtar Kelimeler Simetrik katmanlı ince dikdörtgen kompozit plaklar, Burkulma, RayleighRitz Yöntemi, Parametrik analiz

Özet: $\mathrm{Bu}$ çalışmada simetrik katmanlı ince dikdörtgen kompozit plakların burkulması incelenmiştir. Hesaplamalar, Klasik Laminasyon Plak Teorisi'nin (KLPT) denklemlerine göre RayleighRitz Yöntemi (R-R) ile gerçekleştirilmiştir. Kenarlarından basit mesnetli, düzlemsel yükleme etkisindeki $\left(\mathrm{N}_{\mathrm{x}}\right) 24$ farklı dizilimli kompozit plakın kritik burkulma yükü $\left(\mathrm{N}_{\mathrm{kr}}\right), 12$ farklı kenar oranı (a/b ve b/a) için parametrik olarak hesaplanmıștır. Sonuçlar Sonlu Elemanlar Yöntemi (SEY) temelli ANSYS paket yazılımı sonuçlarıyla karşılaştırılmış ve yakın sonuçlar elde edilmiştir. $\mathrm{Bu}$ çalışmanın amacı; hazırlanan boyutsuz tabloların kullanımıyla uygun plak tiplerinin bulunması ve kompozit teknelerin yapısal ön tasarımında kullanılacak pratik bilgiler elde edilmesidir. Böylelikle üretim sırasında, malzeme, iş gücü, zaman ve test maliyetlerinden tasarruf edilmesi öngörülmüștür.

\section{Buckling of Symmetrically Laminated Thin Rectangular Composite Plates}

\begin{tabular}{ll}
\hline $\begin{array}{l}\text { Keywords } \\
\text { Symmetrically } \\
\text { laminated thin }\end{array}$ & $\begin{array}{l}\text { Abstract: Critical buckling loads of symmetrically laminated thin } \\
\text { rectangular composite plates were examined in this study. } \\
\text { rectangular }\end{array}$ \\
$\begin{array}{l}\text { Ramposite plates, } \\
\text { Ruckling, }\end{array}$ & $\begin{array}{l}\text { equations based on Classical Laminated Plate Theory. Critical } \\
\text { buckling loads of 24 differently laminated simply supported plates }\end{array}$ \\
$\begin{array}{l}\text { Rayleigh-Ritz } \\
\text { Method, }\end{array}$ & with in-plane force at the edge were calculated parametrically for \\
Parametric & obtained by ANSYS software package based on Finite Element \\
Analysis & Method, which seem to be approximate. The aim of this study was \\
& mainly to find the most suitable lamination type of plates. Non- \\
& dimensionally tabulated results were given for practical use at the \\
preliminary structural design stage of composite vessels. Thus, it \\
is expected to save material, labor, time and test costs during \\
production stage.
\end{tabular}

*Sorumlu yazar: erkin.altunsaray@deu.edu.tr 


\section{Giriş}

Katmanlı kompozit plaklar, yapı elemanlarınca desteklenen plaklardan oluşan gemi, uçak gibi mühendislik yapılarında, malzeme ve üretim yöntemlerindeki gelişmelere paralel olarak artan bir ivmeyle kullanılmaktadır. Katmanlı kompozit plakların denizcilik alanında kullanımları çeşitli araştırmacıların çalışmalarında sunulmuştur [1-4].

Gemi yapısı, çeşitli normal ve derin elemanlarca (posta, kemere, tülani vb.) desteklenen panellerden oluşur. Destek elemanların arasında kalan elemanların plakların (güverte, borda, perde, dip yapısı vb.) kısa kenarının kalınlığına oranı büyük olduğu için ince plak kabulüyle hesaplamalar yapılır. Destek elemanlarının sıralanmasına göre enine, boyuna ve karışı yapı sistemleri bulunmaktadır [5]. Gemiler dalgalar boyunca ilerlerken, dalga tepesinde sarkma dolayısıyla dip yapısında burkulma yüküne, dalga çukurunda ise çökme buna bağlı olarak da güvertede burkulma yüküne maruz kalır. Dip yapısının güverteye oranla çok daha mukavim yapılmasından dolayl; güvertedeki kritik burkulma yükünün incelenmesi araștırmacılar tarafindan önem taşımaktadır. Klasik Plak Teorisi'nin (KPT) katmanlı kompozitlere uyarlanmış hali olan Klasik Laminasyon Plak Teorisi (KLPT)'nin incelemelerde plak kısa kenarının plak kalınlığına oranı düşük olan ince plaklar için uygun olduğu belirtilmiştir [6]. Deniz ortamındaki çevresel etkilere yüksek dayanım sağlamak için kompozit gemilerde kıvrımsız, dikilmiş, genellikle $-45^{0}, 0^{0},+45^{0}, 90^{\circ}$ açılarında dizilmiş çok eksenli elyafların, termoset reçinelerle (polyester, epoksi, vinilester vd.) birleștirildiği yapı sistemi kullanılmaktadır. Orta simetri düzlemine göre uzaklıkları, açıları ve mekanik özellikleri aynı olan yapı, simetrik katmanlı olarak adlandırılır. Simetrik katmanlı kompozit plakların kompozit yapılarda tercih edilmesinin en önemli nedeni, üretimde sertleşme sonrası isıl gerilmelerin neden olduğu büzülmelerin gerçekleşmemesidir [7-11]. Üç veya daha fazla sayıda aynı malzemeden oluşan tabakaların plak içinde orta simetri düzlemine göre aynı miktarlarda dağılımıyla oluşan kuazi-izotropik plaklarda elyaf açıları $(\theta), \theta=\mathrm{i} \pi / \mathrm{I}$ olarak tanımlanmaktadır. i= 1,2,I ve I elyafların dizilim açılarının toplam adedidir $(I \geq 3)$.

Lekhnitskii [7], ortotropik plakların stabilitesini Klasik Laminasyon Plak Teorisi'ne (KLPT) göre, Ambartsumyan [12] ise kayma deformasyon etkilerini dikkate alarak incelemiștir. Baharlou ve Leissa [13] farklı sınır koşullarındaki ortotropik plakların titreşim ve burkulma problemlerini Rayleigh-Ritz Yöntemi ile çözmüșlerdir. Lakshminarayana ve arkadaşları [14] simetrik katmanlı kuazi-izotropik eliptik ve dairesel delikli dikdörtgen plakların burkulmasını Sonlu Elemanlar Yöntemi ile incelemişlerdir. Çalışmalarında grafit/epoksi plakların, sınır koşullarının ve delik oryantasyonun burkulma yüküne etkisini araştırmışlardır. Hu ve arkadaşları [15] parabolik ve sabit eksenel yükler altındaki grafit/epoksi dikdörtgen kompozit plakların burkulmasını, Klasik Laminasyon Plak Teorisi'ne göre Rayleigh-Ritz Yöntemi'yle çözmüşlerdir. Darvizeh ve arkadaşları [16], Genelleştirilmiş Diferansiyel Quadrature Yöntemi ve Rayleigh-Ritz Yöntemi'yle grafit/epoksi malzemeli farklı dizilimlerdeki kompozit plakların burkulmasını hesaplamışlardır. Aydoğdu [17] basit mesnetli, çapraz katmanlı kompozit plakların eğilme, burkulma ve titreşimi üzerine geliştirdiği kayma deformasyon teorisini sunmuştur. Felix ve arkadaşları [18] ortotropik dikdörtgen ince plakların burkulmasını ve titreşimini Rayleigh-Ritz Yöntemi ve Sonlu Elemanlar Yöntemi'yle incelemişlerdir. Aydoğdu ve Tımarcı [19] 
Düzlem-içi yüklenmiş basit mesnetli simetrik katmanlı dikdörtgen kompozit ince plakların burkulmasını ve titreşimini, Klasik Plak Teorisi'ne göre Ritz Yöntemi'yle araştırmışlardır. Aydogdu ve Aksencer [20] doğrusal değişen düzlem içi yükleme etkisindeki, dik katmanlı kompozit plakların burkulmasını incelemişlerdir. Yükleme kenarları basit mesnet diğer kenarları çeşitli sınır koşullarındaki plakları Ritz Yöntemi'yle araştırmışlardır. Kumar [21] literatür derleme makalesinde, kabuk, plak ve kirişlerin, dinamik, statik ve burkulma problemlerinde Rayleigh-Ritz Yöntemi'nin kullanımını araştırmıştır.

$\begin{array}{ccr}\text { Literatürde, } & \text { kompozit } & \text { plakların } \\ \text { burkulması } & \text { üzerine } & \text { yapılan }\end{array}$ araştırmaların büyük çoğunluğu özel ortotropik plakların, farklı teorilerle incelenmesidir [22-24]. Altunsaray ve Bayer [25] $-45^{\circ}, 0^{\circ}, 45^{\circ}, 90^{\circ}$ açlarının 24 farklı dizilimiyle elde edilen simetrik katmanlı kuazi-izotropik plakların, Galerkin Yöntemi'yle "tek terim" için ve levha kenarlarının 3'te biri aralıklarda ayrıklaştırılmasıyla Sonlu Farklar Yöntemi'ni uygulayarak kritik burkulma yüklerini hesaplamışlardır. Sonlu Elemanlar Yöntemi temelli ANSYS paket yazılımıyla bulunan sonuçlarla karşılaştırmışlardır. 10 plak tipi için 3 yöntemle birbirine yaklaşık sonuç bulunamadığından çalışmada 14 plak tipinin sonuçları sunulm1uştur.

$\mathrm{Bu}$ makalede önceki çalışmada [25] sunulmamış plak tiplerini de kapsayan 24 farklı dizilimli simetrik katmanlı ince dikdörtgen kompozit plakların RayleighRitz Yöntemi'yle burkulma analizi gerçekleştirilmiştir. KLPT teorisine göre Rayleigh-Ritz Yöntemi'yle 1, 2, 3, 4 ve 9 terim alınarak yakınsaklı analizi yapılmıștır. Rayleigh-Ritz Yöntemi ile gerçekleştirilen analizler, SEY temelli ANSYS paket yazılımı sonuçlarıyla karşılaştırılmış yakın sonuçlar elde edilmiştir.
Kompozit gemilerde, enine ve boyuna elemanlarla desteklenen güvertenin sınır şartları basit mesnetle ankastre mesnet arasında olmakla birlikte, burkulma analizlerinde basit mesnetli seçilerek sonuçların daha güvenli sahada olması öngörülmüştür. 24 farklı laminasyon tipinde sıralanmış orta simetri düzlemine göre simetrik katmanlı plakların, farklı kenar oranlarının ve laminasyon tiplerinin kritik burkulma yüküne etkisi parametrik olarak incelenmiştir. Hazırlanan boyutsuz tablolarla kompozit gemilerin yapısal ön tasarımında uygun plak tipleri hızlı biçimde elde edilip, zaman, iş gücü, malzeme ve deney masraflarından tasarruf edilmesi öngörülmüştür.

\section{Materyal ve Metot}

2.1. Analizlerde incelenen plak geometrisi, yükleme durumları, kenar oranları, katmanların sıralanma açıları ve malzemenin mekanik özellikleri

Parametrik analizlerde, $\mathrm{x}$ doğrultunda karşılıklı iki kenarından tek eksenli $\left(\mathrm{N}_{\mathrm{x}}\right)$ basmaya maruz plaklar incelenmiștir. Plak geometrisi, kartezyen koordinatlarda Şekil 1.'de gösterilmiştir. Kartezyen koordinatlarda fiber (elyaf) doğrultusu ve genel eksenle yaptığ " $\theta$ " açısı Şekil 2.'de gösterilmiştir.

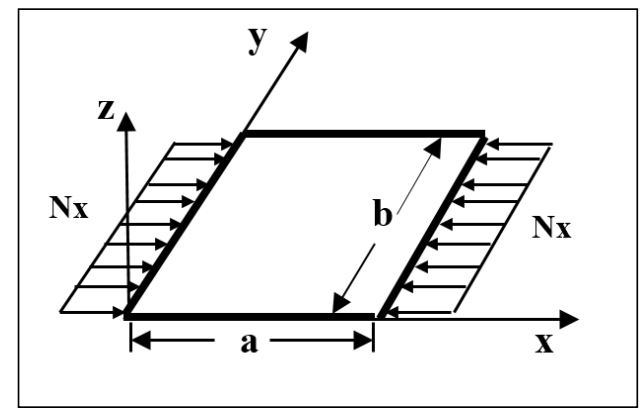

Şekil 1. Kartezyen koordinatlarda tek eksenli basmaya maruz plak ( $\mathrm{N}_{\mathrm{x}}$ etkisinde) 


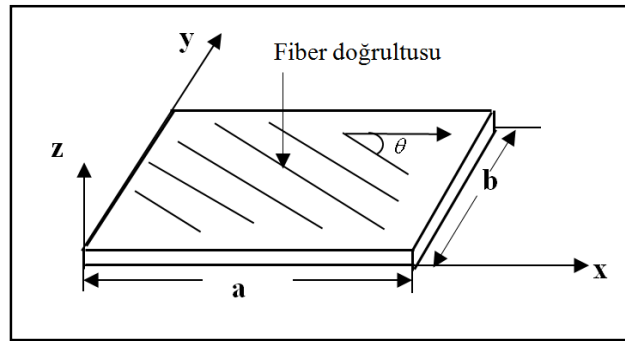

Sekil 2. Kartezyen koordinatlarda fiber (elyaf) doğrultusu ve $\theta$ açısı

Çalışmada incelenen kenar oranları Tablo 1.'de gösterilmiștir. SEY (ANSYS) Ile yapılan karşılaştırmalarda plak kısa kenarı 0,2 m. seçilmiştir. Katmanları -450,
$0^{0},+45^{0}$ ve $90^{0}$ açılarının birlikte kullanıldığı 24 farklı plak tipi Tablo 2.'de sunulmuștur. "LT" laminasyon tipini, " $n$ " seçilen o katmandan kaç adet olduğunu ve "s" ise orta simetri düzlemine göre simetriyi göstermektedir. Bu çalışmada $\mathrm{n}$ $=2$ seçilmiştir.

Tablo 1. Parametrik analizlerde incelenen kenar oranları

\begin{tabular}{lllllll}
\hline $\mathrm{a} / \mathrm{b}$ & 1 & 1,2 & 1,4 & 1,6 & 1,8 & 2 \\
\hline $\mathrm{b} / \mathrm{a}$ & 1 & 1,2 & 1,6 & 1,6 & 1,8 & 2
\end{tabular}

Tablo 2. Tabakaları farklı açılarda sıralanmıș simetrik katmanlı kompozit plak tipleri

\begin{tabular}{llll}
\hline Laminasyon Tipi & Gösterim & Laminasyon Tipi & Gösterim
\end{tabular}

\begin{tabular}{llll} 
LT1 & {$\left[-45_{n} / 0_{n} / 45_{n} / 90_{n}\right]_{s}$} & LT13 & {$\left[45_{n} /-45_{n} / 0_{n} / 90_{n}\right]_{s}$} \\
LT2 & {$\left[-45_{n} / 0_{n} / 90_{2} / 45_{2}\right]_{s}$} & LT14 & {$\left[45_{n} /-45_{n} / 90_{n} / 0_{n}\right]_{s}$} \\
LT3 & {$\left[-45_{n} / 45_{n} / 0_{n} / 90_{n}\right]_{s}$} & LT15 & {$\left[45_{n} / 0_{n} /-45_{n} / 90_{n}\right]_{s}$} \\
LT4 & {$\left[-45_{n} / 45_{n} / 90_{n} / 0_{n}\right]_{s}$} & LT16 & {$\left[45_{n} / 0_{n} / 90_{n} /-45_{n}\right]_{s}$} \\
LT5 & {$\left[-45_{n} / 90_{n} / 0_{n} / 45_{n}\right]_{s}$} & LT17 & {$\left[45_{n} / 90_{n} /-45_{n} / 0_{n}\right]_{s}$} \\
LT6 & {$\left[-45_{n} / 90_{n} / 45_{n} / 0_{n}\right]_{s}$} & LT18 & {$\left[45_{n} / 90_{n} / 0_{n} /-45_{n}\right]_{s}$} \\
LT7 & {$\left[0_{n} /-45_{n} / 45_{n} / 90_{n}\right]_{s}$} & LT19 & {$\left[90_{n} /-45_{n} / 0_{n} / 45_{n}\right]_{s}$} \\
LT8 & {$\left[0_{n} /-45_{n} / 90_{n} / 45_{n}\right]_{s}$} & LT20 & {$\left[90_{n} /-45_{n} / 45_{n} / 0_{n}\right]_{s}$} \\
LT9 & {$\left[0_{n} / 45_{n} /-45_{n} / 90_{n}\right]_{s}$} & LT21 & {$\left[90_{n} / 0_{n} /-45_{n} / 45_{n}\right]_{s}$} \\
LT10 & {$\left[0_{n} / 45_{n} / 90_{n} /-45_{n}\right]_{s}$} & LT22 & {$\left[90_{n} / 0_{n} / 45_{n} /-45_{n}\right]_{s}$} \\
LT11 & {$\left[0_{n} / 90_{n} /-45_{n} / 45_{n}\right]_{s}$} & LT23 & {$\left[90_{n} / 45_{n} /-45_{n} / 0_{n}\right]_{s}$} \\
LT12 & {$\left[0_{n} / 90_{n} / 45_{n} /-45_{n}\right]_{s}$} & LT24 & {$\left[90_{n} / 45_{n} / 0_{n} /-45_{n}\right]_{s}$} \\
\hline
\end{tabular}

Tablo 3. T300-934 kodlu karbon/epoksi malzemenin mekanik özellikleri [26]

Boyuna Young (Elastisite) Modülü $\left(\mathrm{E}_{11}\right)$

Enine Young (Elastisite) Modülü ( $\left.\mathrm{E}_{22}\right)$

Boyuna Kayma Modülü $\left(\mathrm{G}_{12}\right)$

Boyuna Poisson oranı $\left(v_{12}\right)$

Tabaka kalınlığı $(\mathrm{t})$
$148.10^{9}\left(\mathrm{~N} / \mathrm{m}^{2}\right)$

$9,65.10^{9}\left(\mathrm{~N} / \mathrm{m}^{2}\right)$

$4,55 \cdot 10^{9}\left(\mathrm{~N} / \mathrm{m}^{2}\right)$

0.30

$0,185 \cdot 10^{-3}-0,213 \cdot 10^{-3}(\mathrm{~m})$ 
Analizlerdeki incelenen malzeme T300934 kodlu karbon/epoksi malzemenin mekanik özelikleri Tablo 3.'te verilmiştir.

Her bir tabaka kalınlığı $\mathrm{t}=0,2 \cdot 10^{-3} \mathrm{~m}$. seçilmiștir. 16 katmandan olușan kompozit plakın toplam kalınlığ $\mathrm{h}=0,0032$ metredir.

\subsection{Klasik Laminasyon Plak Teorisi (KLPT) ve Rayleigh-Ritz Yöntemi}

$\mathrm{n}$ adet ortotropik tabakanın farklı doğrultularda birleștirilmesiyle oluşturulan, bileşik katmanlı kompozit plaklar, Klasik Laminasyon Plak Teorisi'ne (KLPT) göre incelenir. KLPT Kirchoff Hipotezi varsayımına göre çeşitli kabullere dayanır [27]:

- Katmanlar arasındaki bağlar mükemmeldir, yapıştırma tabakası çok incedir ve tabaka kayma etkisiyle şekil değiștirmez, levha tek bir katman gibi bütün olarak davranır.

- Deformasyondan önce orta yüzeye dik olan düz hatlar (örneğin; enine normaller) deformasyondan sonra da düz kalır. Enine yer değiştirmeler kalınlık koordinat sisteminden bağımsızdır. Enine normal uzama sifirdır. $\varepsilon_{z}=0$

- Enine normallerde kayma yoktur, deformasyondan sonra da orta düzleme dik kalacak biçimde dönerler.

$\gamma_{x z}=\gamma_{y z}=0-\frac{\partial w_{0}}{\partial w_{x}}$

\subsubsection{Yer değiștirme ve şekil} değiştirme ilişkisi

Katmanlı kompozit plaklar incelenirken, belirli kısıtlar dikkate alınır [27].

- Heterojen malzeme yapısı nedeniyle eşdeğer homojen malzemenin etkin elastisite modulü dikkate alınır.

- Plak kalınlığı diğer boyutları yanında çok küçüktür.

- Katmanlar arasında kayma gerilmeleri oluşmaz, alt ve üst yüzeylerdeki kayma gerilmeleri sıfırdır.
-Katmanlar Hooke kanuna uyar, doğrusal elastik yapıdadır, sabit kalınlıktadır ve 3 simetri eksenine sahiptir.

-Şekil değişimleri ve yer değiş̧imleri plak kalınlığı yanında çok küçüktür.

Kirchhoff hipotezine göre levha düzlemi üzerindeki yer değiștirmeler $(\mathrm{u}, \mathrm{v})$ z'nin lineer bir fonksiyonudur. Deformasyondan önce $(x, y, z)$ koordinatlarında olan bir nokta, deformasyondan sonra $(x-u, y+v, z+w)$ noktasına hareket eder. Bileșik tabakanın $\mathrm{x}-\mathrm{z}$ düzlemindeki yer değişimleri Şekil 3.'te gösterilmiştir. Referans düzlemi $\mathrm{z}=0$ orta düzlem olarak adlandırılır. Kirrchoff hipotezine göre küçük yer değişimleri kartezyen koordinatlarda aşağıdaki gibi gösterilir [27].

$$
\begin{aligned}
& u(x, y, z, t)=u_{\circ}(x, y, t)-z \frac{\partial w_{0}}{\partial x} \\
& v(x, y, z, t)=v_{\circ}(x, y, t)-z \frac{\partial w_{0}}{\partial y} \\
& w(x, y, z, t)=w_{\circ}(x, y, t)
\end{aligned}
$$

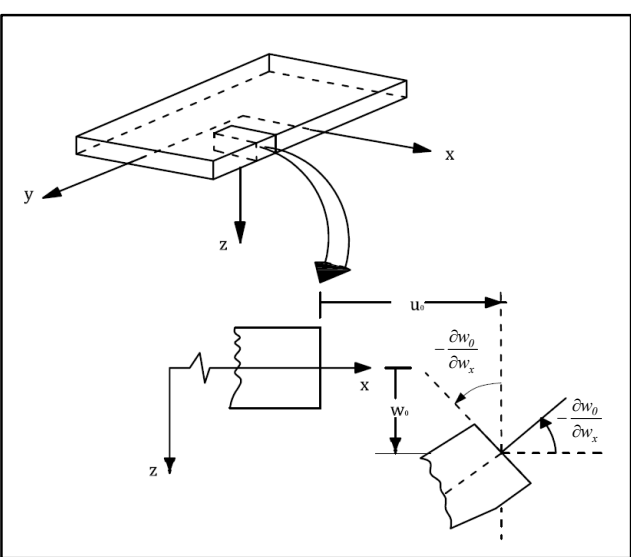

Şekil 3. Katmanlı kompozit plakın $\mathrm{x}-\mathrm{z}$ düzlemindeki yer değişimleri

Bu çalışmadaki plak kısa kenarının plak kalınlığına oranı büyük olduğu için, Klasik Laminasyon Plak Teorisi (KLPT) 
ile inceleme uygun görülmüştür. KLPT'de simetrik katmanlı kompozit plakların burkulmasında eğilme-uzama rijitlik matrisi $B_{i j}$ sıfırdır [27]. Çalışmada sadece düzlem dıșı şekil değiştirmeler gözönüne alınmıştır.
Kompozit plağın toplam enerji fonksiyoneli F; aşağıda verilmiștir [24].

$F=U_{e}-V$ potansiyel enerjisi,

$U_{e}=\frac{1}{2} \int_{0}^{a} \int_{0}^{b}\left[\begin{array}{l}D_{11}\left(\frac{\partial^{2} w}{\partial^{2} x}\right)^{2}+2 D_{12}\left(\frac{\partial^{2} w}{\partial^{2} x}\right)\left(\frac{\partial^{2} w}{\partial^{2} y}\right)+4 D_{66}\left(\frac{\partial^{2} w}{\partial x \partial y}\right)^{2}+D_{22}\left(\frac{\partial^{2} w}{\partial^{2} y}\right)^{2} \\ +4 D_{16}\left(\frac{\partial^{2} w}{\partial^{2} x}\right)^{2}\left(\frac{\partial^{2} w}{\partial x \partial y}\right)+4 D_{26}\left(\frac{\partial^{2} w}{\partial^{2} y}\right)^{2}\left(\frac{\partial^{2} w}{\partial x \partial y}\right)\end{array}\right] d x d y$

Orta simetri düzlemine etki eden kuvvetlerin potansiyel enerjisi $\left(\mathrm{V}_{\mathrm{L}}\right)$ ise aşağıda verilmiştir.

$V=\frac{1}{2} \int_{0}^{a} \int_{0}^{b} N_{x}\left(\frac{\partial w}{\partial x}\right)^{2} d x d y$

Burada " $N_{x}$ " plağın kenarlarında xeksenine paralel olarak etkiyen düzgün yayılı eksenel basınç yükünü ifade etmektedir (Şekil.1). Denklem (3) ve (4)'te "w" çökme fonksiyonunu göstermektedir. Eğilme rijitlik matrisi elemanları $\mathrm{D}_{11}, \mathrm{D}_{12}, \mathrm{D}_{16}, \mathrm{D}_{22}, \mathrm{D}_{26}$ ve $\mathrm{D}_{66}$ (5) denkleminde verildiği gibi hesaplanır [24].
$D_{i j}=\frac{1}{3} \sum_{k=1}^{N} \bar{Q}_{i j}^{(k)}\left(z_{k+1}^{3}-z_{k}^{3}\right)$

Denklem (6)'da verilen $\quad \bar{Q}_{i j}$ dönüşüme uğramış indirgenmiş rijitlik matrisinin elemanları her katmanin genel eksenle yaptığı $\theta$ açısı (Şekil 2.) ve $Q_{i j}$ indirgenmiş rijitlik matrisi elemanlarından (7) faydalanarak her katman için ayrı ayrı hesaplanır [24]. z her bir katmanın orta simetri düzleminden uzaklığıdır (Șekil 4.).

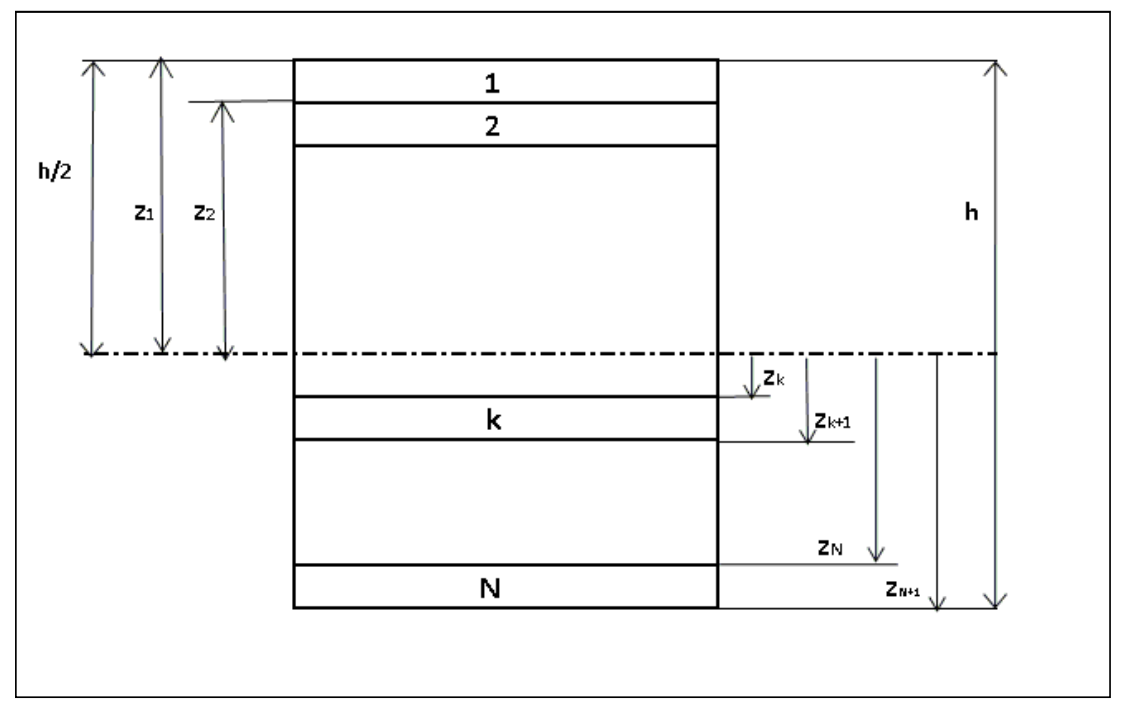

Şekil 4. Katmanların orta simetri düzleminden uzaklıklarının gösterimi 


$$
\begin{gathered}
\bar{Q}_{11}=Q_{11} \cos ^{4}(\theta)+2\left(Q_{12}+2 Q_{66}\right) \sin ^{2}(\theta) \cos ^{2}(\theta)+Q_{22} \sin ^{4}(\theta) \\
\bar{Q}_{12}=\left(Q_{11}+Q_{22}-4 Q_{66}\right) \sin ^{2}(\theta) \cos ^{2}(\theta)+Q_{12}\left(\sin ^{4}(\theta)+\cos ^{4}(\theta)\right) \\
\bar{Q}_{22}=Q_{11} \sin ^{4}(\theta)+2\left(Q_{12}+2 Q_{66}\right) \sin ^{2}(\theta) \cos ^{2}(\theta)+Q_{22} \cos ^{4}(\theta) \\
\bar{Q}_{16}=\left(Q_{11}-Q_{12}-2 Q_{66}\right) \sin (\theta) \cos ^{3}(\theta)+\left(Q_{12}-Q_{22}+2 Q_{66}\right) \sin ^{3}(\theta) \cos (\theta) \\
\bar{Q}_{26}=\left(Q_{11}-Q_{12}-2 Q_{66}\right) \sin ^{3}(\theta) \cos (\theta)+\left(Q_{12}-Q_{22}+2 Q_{66}\right) \sin (\theta) \cos ^{3}(\theta) \\
\bar{Q}_{66}=\left(Q_{11}+Q_{22}-2 Q_{12}-2 Q_{66}\right) \sin ^{2}(\theta) \cos ^{2}(\theta)+Q_{66}\left(\sin ^{4}(\theta)+\cos ^{4}(\theta)\right)
\end{gathered}
$$

Ortotropik malzemeler için $Q_{i j}$ indirgenmiş rijitlik matrisinin mühendislik sabitleri cinsinden yazımı aşağıda verilmiştir [27].

$$
\begin{aligned}
& Q_{11}=E_{11} /\left(1-v_{12} v_{21}\right) \\
& Q_{12}=v_{12} E_{22} /\left(1-v_{12} v_{21}\right) \\
& Q_{22}=E_{22} /\left(1-v_{12} v_{21}\right) \\
& Q_{66}=G_{12}
\end{aligned}
$$

Yukarıdaki (7) ifadesinde yeralan mühendislik sabitleri $\left(\mathrm{E}_{1}, \mathrm{E}_{2} \mathrm{G}_{12}, v_{12}\right.$ ve $v_{21}$ ) sirasiyla $E_{1}$ boyuna elastisite modülü, $\mathrm{E}_{2}$ enine elastisite modülü, $\mathrm{G}_{12}$ boyuna kayma modülü, $v_{12}$ boyuna Poisson oranı ve $v_{21}$ enine Poisson oranıdır. Mühendislik sabitleri, katmanların açıları ve her bir katmanın orta simetri düzleminden uzaklığı, (5) ve (6) ifadelerinde yerine yazılarak (3) ifadesindeki eğilme rijitlik matrisi elemanları $D_{i j}$ belirlenmiş olur. Çalışmada seçilen karbon/epoksi malzemenin mühendislik sabitleri Tablo 3.'te verilmiştir.

Basit mesnetli hal için, plak kenarlarında çökme $(w)$ ve eğilme momenti $\left(\mathrm{M}_{\mathrm{x}}, \mathrm{M}_{\mathrm{y}}\right)$ sifirdır.

$$
\begin{aligned}
& x=0 \text { ve } \mathrm{x}=\mathrm{a}^{\prime} \text { da } \quad w=M_{x}=0 \\
& y=0 \text { ve } \mathrm{y}=\mathrm{b}^{\prime} \text { de } \quad w=M_{y}=0
\end{aligned}
$$

Kenarlara uygulanan eğilme momentleri $M_{x}$ ve $M_{y}$, Ashton ve Whitney [28] tarafından verilmiştir :

$$
\begin{aligned}
& M_{x}=-\left(D_{11} \frac{\partial^{2} w}{\partial x^{2}}+D_{12} \frac{\partial^{2} w}{\partial y^{2}}+2 D_{16} \frac{\partial^{2} w}{\partial x \partial y}\right)=0 \\
& M_{y}=-\left(D_{12} \frac{\partial^{2} w}{\partial x^{2}}+D_{22} \frac{\partial^{2} w}{\partial y^{2}}+2 D_{26} \frac{\partial^{2} w}{\partial x \partial y}\right)=0
\end{aligned}
$$

Sınır boyunca çökmenin sıfır olması, çökmenin türevlerinin de (sınırda alınan teğetlerin eğimi değişmeyeceğinden) sıfır olmasını gerektirir. Böylece denklem 8 aşağıdaki ifadeye indirgenir:

$$
\begin{array}{ll}
x=0, \text { a boyunca } & w=\frac{\partial^{2} w}{\partial x^{2}}=0 \\
y=0, \text { b boyunca } & w=\frac{\partial^{2} w}{\partial y^{2}}=0
\end{array}
$$

Geometrik sınır şartlarını sağlayacak şekilde seçilen trigonometrik yaklaşım fonksiyonu $\phi_{m n}$ aşağıda gösterilmiştir [24].

$$
\begin{aligned}
& \phi_{m n}=\sin \left(\frac{m \pi x}{a}\right) \sin \left(\frac{n \pi y}{b}\right) \\
& w(x, y)=\sum_{m=1}^{M} \sum_{n=1}^{N} C_{m n} \phi_{m n}
\end{aligned}
$$

Yukarıdaki eşitlikte $C_{m n}$ bilinmeyen sabitlerdir. Çökme fonksiyonu $w(x, y)$ 
(12), enerji fonksiyonelinde (2) yerine koyulup, bilinmeyen sabitlere göre minimize edilirse;

$$
\frac{\partial F}{\partial C_{m n}}=0
$$

$C_{m n}$ cinsinden $\mathrm{MxN}$ boyutlu lineer homojen denklem sistemi elde edilir. Bu denklem takımına ait katsayılar matrisinin determinantı sıfır olmalıdır.

$$
(K-\lambda G)\{C\}=0
$$

burada $\mathrm{K}$ rijitlik matrisi, $\mathrm{G}$ geometri matrisi ve $\lambda$ ise burkulma yüküdür. Özdeğer problemi sonucunda elde edilen en küçük $\lambda\left(\mathrm{N}_{\mathrm{kr}}\right)$ değeri kritik burkulma yüküdür.

\subsection{Sonlu Elemanlar Yöntemi'yle (SEY) hesaplama yapan ANSYS paket yazılımı'nın kullanımı}

$\mathrm{Bu}$ çalışmadaki ANSYS yazılımı, Rayleigh-Ritz Yöntemi ile yapılan analizlerle karşılaștırma yapmak için kullanılmıştır. Yazılımda, kompozit plakların analizleri için önerilen "SHELL-181" kodlu dikdörtgen geometriye sahip, 4 düğüm noktalı kabuk eleman seçilmiştir [29]. Plak kısa kenarı 0,2 m. seçilmiş, eleman kenarının plak kısa kenarına oranı $1 / 20$ olan kare ağ yapısı (mesh) uygulanmıștır. SHELL181 Birinci Mertebe Kayma Deformasyon Teorisi'ne göre yer değiştirmektedir.

\section{Bulgular}

\subsection{Sayısal analiz sonuçları}

$\mathrm{Bu}$ çalışmada dört kenarından basit mesnetli simetrik katmanlı dikdörtgen ince plakların burkulması incelenmiştir. Plak kısa kenarının plak kalınlığına oranı büyük olduğu için ince kompozit plaklar için geliştirilmiş̧ Klasik
Laminasyon Plak Teorisi (KLPT) ile incelemeler için uygun görülmüştür.

Sayısal analizlerde önemli bir enerji yöntemi olan Rayleigh-Ritz Yöntemi ve Sonlu Elemanlar Yöntemi (SEY) temelli ANSYS paket yazılımı kullanılmıștır. Düzgün yayılı eksenel yük $\left(\mathrm{N}_{\mathrm{x}}\right)$ etkisindeki 24 farklı plak, 12 farklı kenar oranı (a/b ve b/a) için parametrik olarak incelenmiștir. Her durum için kritik burkulma yükü $\mathrm{N}_{\mathrm{kr}}$ bulunmuştur. Sonuçlar Tablo 6.-7.'de verilmiştir.

Rayleigh-Ritz Yöntemi ile bulunan sonuçlar, SEY (ANSYS) ile elde edilenlerle yakın çıkmıștır. LT3 kodlu [$\left.45_{2} / 45_{2} / 0_{2} / 90_{2}\right]_{s}$ plak için Rayleigh-Ritz Yöntemi'yle farklı kenar oranları için yapılan yakınsaklık analizi $(1,2,3$, 4 ve 9 terim için) Tablo 4.'te gösterilmiştir. 3 terim ve 4 terim alınarak bulunan sonuçların arasında süreksizlik görünmektedir. Bunun nedeni Ritz Yöntemi'yle 3 terim için yapılan hesaplamalarda D16 ve D26 eğilmeburulma birleșim rijitlik sabitlerinin sadeleşmesi, 4 terim için yapılanlarda ise bu terimlerin kalması sonucundadır. $\mathrm{Bu}$ farklılık Tablo 5'te gösterilmiştir. Bu çalışmada optimum çözüm süresinde kabul edilebilir yaklașıklık sağlandığı için 4 terimli hesaplama yeterli görülmüștür. Daha yakın sonuçlar elde etmek için terim sayısını arttırmak gerekecektir ancak bu durumda da çözümleme süresi çok daha uzun olacak ve yüksek işlemci kapasiteli bilgisayar kullanılması gerekli olacaktır.

Cok sayıda değișkenin bulunduğu parametrik analizlerde; Rayleigh-Ritz Yöntemi'yle yapılan hesaplama süresi, SEY temelli ANSYS paket yazllımiyla yapılandan çok daha kısa sürmüştür. Bunun nedeni ANSYS yazllımının analiz hiyerarşisi gereği önce modelin, ardından ağ yapısının (mesh) oluşturulup son olarak sınır koşullarının 
ve yüklerin girilip, sonuçların elde edilmesidir.

Tablo 6.-7.'den görüldüğü üzere Rayleigh-Ritz Yöntemi ve SEY ile yapılan hesaplamalarda LT1, LT2, LT3, LT4, LT5, LT6, LT7, LT8, LT11, LT19, LT20, LT21 plakları, sırasıyla LT15, LT16, LT13, LT14, LT18, LT17, LT9, LT10, LT12, LT24, LT23, LT22 plakları ile aynı kritik burkulma yükü değerlerini vermişlerdir.

Tablo 6.'dan kritik burkulma yükü $\left(\mathrm{N}_{\mathrm{kr}}\right)$, kısa kenar " $y$ " eksenindeki durumda görüldüğü gibi; kenar oranı artmasıyla kritik burkulma yükü artmaktadır. Kritik burkulma yükü $\left(\mathrm{N}_{\mathrm{kr}}\right)$ 'in en yüksek olduğu durum, kenar oranı $\mathrm{a} / \mathrm{b}=2$ olduğunda LT20 $\left[90_{2} /-45_{2} / 45_{2} / 0_{2}\right] \mathrm{s}$ )ve LT23 ([90 $\left.2 / 45_{2} /-45_{2} / 0_{2}\right]$ s $)$ kodlu plaklarda gözlenmiștir. Bu laminasyon tipindeki plaklar için kritik burkulma yükü $\left(\mathrm{N}_{\mathrm{kr}}\right) 356785 \mathrm{~N} / \mathrm{m}$ değerindedir. En küçük kritik burkulma yükü $\left(\mathrm{N}_{\mathrm{kr}}\right)$ değerini veren plaklar ise $a / b=1$ için $133744 \mathrm{~N} / \mathrm{m}$ değeriyle LT11 $\left(\left[0_{2} / 90_{2} /-\right.\right.$ $\left.\left.45_{2} / 45_{2}\right] \mathrm{s}\right)$ ve LT12 ([0 $2 / 90_{2} / 45_{2} /-$ $\left.45_{2}\right]$ s) laminasyon tipindeki plaklardır.

Tablo 4. LT3 Plakının Rayleigh-Ritz Yöntemi ile yapılan yakınsaklık analizi

\begin{tabular}{cccccc} 
& \multicolumn{5}{c}{ Kritik Burkulma Yükü $\mathrm{N}_{\mathrm{kr}}(\mathrm{N} / \mathrm{m})$} \\
\cline { 2 - 6 } $\mathrm{a} / \mathrm{b}$ & 1 & 2 & 3 & 4 & 9 \\
\hline 1 & 202360 & 202360 & 202360 & 198665 & 198142 \\
1.2 & 203599 & 203599 & 203599 & 199804 & 199232 \\
1.4 & 211782 & 211782 & 211782 & 207838 & 207195 \\
1.6 & 224757 & 224757 & 224757 & 220641 & 211234 \\
1.8 & 241497 & 241497 & 241497 & 237202 & 203879 \\
2 & 261458 & 261458 & 261458 & 256988 & 200612 \\
\hline $\mathrm{b} / \mathrm{a}$ & 1 & 2 & 3 & 4 & 9 \\
\hline 1 & 202360 & 202360 & 202360 & 198665 & 198142 \\
1.2 & 145939 & 145939 & 145939 & 143385 & 143043 \\
1.4 & 114554 & 114554 & 114554 & 112655 & 112412 \\
1.6 & 95245 & 95245 & 95245 & 93761 & 93578 \\
1.8 & 82489 & 82489 & 82489 & 81290 & 81146 \\
2 & 73606 & 73606 & 73606 & 72612 & 72495 \\
\hline
\end{tabular}

Tablo 7.'den kritik burkulma yükü $\left(\mathrm{N}_{\mathrm{kr}}\right)$, kısa kenar " $\mathrm{x}$ " ekseninde olduğu durumda görüldüğü üzere; kenar oranının artmasıyla kritik burkulma yükü azalmaktadır. Kritik burkulma yükünün $\left(\mathrm{N}_{\mathrm{kr}}\right)$ en yüksek olduğu durum, kenar oranı $b / a=1$ olduğunda LT3 $\left(\left[-45_{2} / 45_{2} / 0_{2} / 90_{2}\right]_{s}\right)$, LT4 $\left(\left[45_{2} / 45_{2} / 90_{2} / 0_{2}\right]_{\mathrm{s}}\right)$, LT13 ([45 $/$ $\left.45_{2} / 0_{2} / 90_{2}\right]_{s}$ ) ve
LT14 ([45 $\left.\left./-45_{2} / 90_{2} / 0_{2}\right]_{\mathrm{s}}\right) \quad$ kodlu plaklar için gözlenmiştir. $\mathrm{Bu}$ laminasyon tipindeki plaklar için kenar oranı b/a=1 için kritik burkulma yükü $\left(\mathrm{N}_{\mathrm{kr}}\right) 198665 \mathrm{~N} / \mathrm{m}$ değerindedir. Bu durumda en küçük kritik burkulma yükü $\left(\mathrm{N}_{\mathrm{kr}}\right)$ kenar oranı $\mathrm{b} / \mathrm{a}=2$ için LT19 ([90 $\left.\left.2 /-45_{2} / 0_{2} / 45_{2}\right] \mathrm{s}\right)$ ve LT24 ([90 $\left.\left.2 / 45_{2} / 0_{2} /-45_{2}\right] \mathrm{s}\right) \quad$ laminasyon 
tipindeki plaklarda $40707 \mathrm{~N} / \mathrm{m}$ değerindedir.

Tablo 5. 3 terim ve 4 terim için yapılan analizlerde bulunan kritik burkulma yükü

\begin{tabular}{|c|c|}
\hline $\begin{array}{l}\text { Terim } \\
\text { Sayısı }\end{array}$ & Kritik Burkulma Yükü $\mathbf{N}_{\mathrm{kr}}$ \\
\hline \multirow{2}{*}{3} & $b^{4} \mathrm{D} 11 \pi^{2}+2 a^{2} b^{2} \mathrm{D} 12 \pi^{2}+a^{4} \mathrm{D} 22 \pi^{2}+4 a^{2} b^{2} \mathrm{D} 66 \pi^{2}$ \\
\hline & $a^{2} b^{4}$ \\
\hline \multirow{8}{*}{4} & $N \rightarrow \frac{1}{18 a^{4} b^{8}}\left(45 a^{2} b^{8} \mathrm{D} 11 \pi^{2}+90 a^{4} b^{6} \mathrm{D} 12 \pi^{2}+45 a^{6} b^{4} \mathrm{D} 22 \pi^{2}\right.$ \\
\hline & $+180 a^{4} b^{6} \mathrm{D} 66 \pi^{2} \quad \sqrt{\left(409600 a^{6} b^{1}{ }^{4} \mathrm{D} 16^{2}\right.}$ \\
\hline & $+819200 a^{8} b^{1} \mathrm{D} 16 \mathrm{D} 26+409600 a^{1} b^{1} \mathrm{D} 26^{2}$ \\
\hline & $+729 a^{4} b^{1}$ D1 $11^{2} \pi^{4}+2916 a^{6} b^{1}{ }^{4} \mathrm{D} 11 \mathrm{D} 12 \pi^{4}$ \\
\hline & $+2916 a^{8} b^{1}{ }^{2} \mathrm{D} 12^{2} \pi^{4}+1458 a^{8} b^{1} \mathrm{D} 11 \mathrm{D} 22 \pi^{4}$ \\
\hline & $+2916 a^{1} b^{1}$ D $12 \mathrm{D} 22 \pi^{4}+729 a^{1} b^{8} \mathrm{D} 22^{2} \pi^{4}$ \\
\hline & $+5832 a^{6} b^{1}{ }^{4} \mathrm{D} 11 \mathrm{D} 66 \pi^{4}+11664 a^{8} b^{1} \mathrm{D} 12 \mathrm{D} 66 \pi^{4}$ \\
\hline & $\left.\left.+5832 a^{1} b^{1} \mathrm{D} 22 \mathrm{D} 66 \pi^{4}+11664 a^{8} b^{1}{ }^{2} \mathrm{D} 66^{2} \pi^{4}\right)\right)$ \\
\hline
\end{tabular}

Tablo 6. Kritik Burkulma Yükü $\mathrm{N}_{\mathrm{kr}}(\mathrm{N} / \mathrm{m})$, kısa kenar "y" ekseninde

\begin{tabular}{|c|c|c|c|c|c|c|c|}
\hline \multirow{3}{*}{$\begin{array}{c}\text { Kenar } \\
\text { oranı } \\
(a / b)\end{array}$} & \multirow{3}{*}{ YÖNTEM } & \multicolumn{6}{|c|}{ Laminasyon Tipi } \\
\hline & & LT1 & LT2 & LT3 & LT4 & LT5 & LT6 \\
\hline & & $\mathrm{N}_{\mathrm{kr}}$ & $\mathrm{N}_{\mathrm{kr}}$ & $\mathrm{N}_{\mathrm{kr}}$ & $\mathrm{N}_{\mathrm{kr}}$ & $\mathrm{N}_{\mathrm{kr}}$ & $\mathrm{N}_{\mathrm{kr}}$ \\
\hline \multirow[t]{2}{*}{1.00} & Rayleigh-Ritz & 174309 & 160364 & 198665 & 198665 & 160364 & 174309 \\
\hline & SEY(ANSYS) & 165240 & 147060 & 194881 & 194846 & 146759 & 164923 \\
\hline \multirow[t]{2}{*}{1.20} & Rayleigh-Ritz & 168914 & 158538 & 199804 & 206475 & 172770 & 189683 \\
\hline & SEY(ANSYS) & 159690 & 144873 & 196319 & 202943 & 159499 & 180634 \\
\hline \multirow[t]{2}{*}{1.40} & Rayleigh-Ritz & 171629 & 165105 & 207838 & 220804 & 192660 & 211926 \\
\hline & SEY(ANSYS) & 162160 & 151050 & 204540 & 217460 & 179290 & 203657 \\
\hline \multirow[t]{2}{*}{1.60} & Rayleigh-Ritz & 179609 & 177344 & 220641 & 240029 & 218352 & 239731 \\
\hline & SEY(ANSYS) & 169810 & 162714 & 217461 & 235507 & 205613 & 230997 \\
\hline \multirow[t]{2}{*}{1.80} & Rayleigh-Ritz & 191504 & 193958 & 237202 & 263380 & 249047 & 272482 \\
\hline & SEY(ANSYS) & 181130 & 177337 & 233730 & 260340 & 235594 & 264717 \\
\hline \multirow[t]{2}{*}{2.00} & Rayleigh-Ritz & 206603 & 214261 & 256988 & 290448 & 284331 & 309853 \\
\hline & SEY(ANSYS) & 193358 & 201640 & 254141 & 287457 & 271414 & 300908 \\
\hline \multirow{3}{*}{$\begin{array}{l}\text { Kenar } \\
\text { oranı } \\
(\mathrm{a} / \mathrm{b})\end{array}$} & \multirow{3}{*}{ YÖNTEM } & \multicolumn{6}{|c|}{ Laminasyon Tipi } \\
\hline & & LT7 & LT8 & LT9 & LT10 & LT11 & LT12 \\
\hline & & $\mathrm{N}_{\mathrm{kr}}$ & $\mathrm{N}_{\mathrm{kr}}$ & $\mathrm{N}_{\mathrm{kr}}$ & $\mathrm{N}_{\mathrm{kr}}$ & $\mathrm{N}_{\mathrm{kr}}$ & $\mathrm{N}_{\mathrm{kr}}$ \\
\hline \multirow[t]{2}{*}{1.00} & Rayleigh-Ritz & 157781 & 146448 & 157781 & 146448 & 133744 & 133744 \\
\hline & SEY(ANSYS) & 155872 & 143071 & 155872 & 143071 & 133201 & 133201 \\
\hline \multirow[t]{2}{*}{1.20} & Rayleigh-Ritz & 143794 & 135774 & 143794 & 135774 & 130679 & 130679 \\
\hline & SEY(ANSYS) & 142074 & 132454 & 142074 & 132454 & 130296 & 130296 \\
\hline \multirow[t]{2}{*}{1.40} & Rayleigh-Ritz & 139813 & 135424 & 139813 & 135424 & 138365 & 138365 \\
\hline & SEY(ANSYS) & 138197 & 132108 & 138197 & 132108 & 138107 & 138107 \\
\hline \multirow[t]{2}{*}{1.60} & Rayleigh-Ritz & 141845 & 141527 & 141845 & 141527 & 153181 & 153181 \\
\hline & SEY(ANSYS) & 140297 & 138196 & 140297 & 138196 & 153036 & 153036 \\
\hline \multirow[t]{2}{*}{1.80} & Rayleigh-Ritz & 147983 & 152222 & 147983 & 152222 & 173393 & 173393 \\
\hline & SEY(ANSYS) & 146487 & 148857 & 146487 & 148857 & 173360 & 173360 \\
\hline \multirow[t]{2}{*}{2.00} & Rayleigh-Ritz & 157221 & 166520 & 157221 & 166520 & 198089 & 198089 \\
\hline & SEY(ANSYS) & 155766 & 163065 & 155766 & 163065 & 198175 & 198175 \\
\hline
\end{tabular}


Tablo 6. devamı Kritik Burkulma Yükü $\mathrm{N}_{\mathrm{kr}}(\mathrm{N} / \mathrm{m})$, kısa kenar "y" ekseninde

\begin{tabular}{|c|c|c|c|c|c|c|c|}
\hline \multirow{3}{*}{$\begin{array}{l}\text { Kenar } \\
\text { oranı } \\
(\mathbf{a} / \mathbf{b})\end{array}$} & \multirow{3}{*}{ YÖNTEM } & \multicolumn{6}{|c|}{ Laminasyon Tipi } \\
\hline & & LT13 & LT14 & LT15 & LT16 & LT17 & LT18 \\
\hline & & $\mathrm{N}_{\mathrm{kr}}$ & $\mathrm{N}_{\mathrm{kr}}$ & $\mathrm{N}_{\mathrm{kr}}$ & $\mathrm{N}_{\mathrm{kr}}$ & $\mathrm{N}_{\mathrm{kr}}$ & $\mathrm{N}_{\mathrm{kr}}$ \\
\hline \multirow[t]{2}{*}{1.00} & Rayleigh-Ritz & 198665 & 198665 & 174309 & 160364 & 174309 & 160364 \\
\hline & SEY(ANSYS) & 194881 & 194846 & 165240 & 147060 & 164923 & 146759 \\
\hline \multirow[t]{2}{*}{1.20} & Rayleigh-Ritz & 199804 & 206475 & 168914 & 158538 & 189683 & 172770 \\
\hline & SEY(ANSYS) & 196319 & 202943 & 159690 & 144873 & 180634 & 159499 \\
\hline \multirow[t]{2}{*}{1.40} & Rayleigh-Ritz & 207838 & 220804 & 171629 & 165105 & 211926 & 192660 \\
\hline & SEY(ANSYS) & 204540 & 217460 & 162160 & 151050 & 203657 & 179290 \\
\hline \multirow[t]{2}{*}{1.60} & Rayleigh-Ritz & 220641 & 240029 & 179609 & 177344 & 239731 & 218352 \\
\hline & SEY(ANSYS) & 217461 & 235507 & 169810 & 162714 & 230997 & 205613 \\
\hline \multirow[t]{2}{*}{1.80} & Rayleigh-Ritz & 237202 & 263380 & 191504 & 193958 & 272482 & 249047 \\
\hline & SEY(ANSYS) & 233730 & 260340 & 181130 & 177337 & 264717 & 235594 \\
\hline \multirow[t]{2}{*}{2.00} & Rayleigh-Ritz & 256988 & 290448 & 206603 & 214261 & 309853 & 284331 \\
\hline & SEY(ANSYS) & 254141 & 287457 & 193358 & 201640 & 300908 & 271414 \\
\hline \multirow{3}{*}{$\begin{array}{l}\text { Kenar } \\
\text { oranı } \\
(\mathbf{a} / \mathbf{b})\end{array}$} & \multirow{3}{*}{ YÖNTEM } & \multicolumn{6}{|c|}{ Laminasyon Tipi } \\
\hline & & LT19 & LT20 & LT21 & LT22 & LT23 & LT24 \\
\hline & & $\mathrm{N}_{\mathrm{kr}}$ & $\mathrm{N}_{\mathrm{kr}}$ & $\mathrm{N}_{\mathrm{kr}}$ & $\mathrm{N}_{\mathrm{kr}}$ & $\mathrm{N}_{\mathrm{kr}}$ & $\mathrm{N}_{\mathrm{kr}}$ \\
\hline \multirow[t]{2}{*}{1.00} & Rayleigh-Ritz & 146448 & 157781 & 133744 & 133744 & 157781 & 146448 \\
\hline & SEY(ANSYS) & 142903 & 155762 & 133193 & 133193 & 155762 & 142903 \\
\hline \multirow[t]{2}{*}{1.20} & Rayleigh-Ritz & 169548 & 183612 & 150426 & 150426 & 183612 & 169548 \\
\hline & SEY(ANSYS) & 166155 & 181732 & 149996 & 149996 & 181732 & 166155 \\
\hline \multirow[t]{2}{*}{1.40} & Rayleigh-Ritz & 200941 & 217184 & 176743 & 176743 & 217184 & 200941 \\
\hline & SEY(ANSYS) & 197620 & 215415 & 176426 & 176426 & 215415 & 197620 \\
\hline \multirow[t]{2}{*}{1.60} & Rayleigh-Ritz & 239281 & 257512 & 210572 & 210572 & 257512 & 239281 \\
\hline & SEY(ANSYS) & 235945 & 255828 & 210368 & 210368 & 255828 & 235945 \\
\hline \multirow[t]{2}{*}{1.80} & Rayleigh-Ritz & 283935 & 304127 & 250902 & 250902 & 304127 & 283935 \\
\hline & SEY(ANSYS) & 280554 & 302473 & 250814 & 250814 & 302473 & 280554 \\
\hline \multirow[t]{2}{*}{2.00} & Rayleigh-Ritz & 334576 & 356785 & 297201 & 297201 & 356785 & 334576 \\
\hline & SEY(ANSYS) & 332835 & 355136 & 297233 & 297233 & 355136 & 332835 \\
\hline
\end{tabular}

Tablo 7. Kritik Burkulma Yükü $\mathrm{N}_{\mathrm{kr}}(\mathrm{N} / \mathrm{m})$, kısa kenar "x" ekseninde

\begin{tabular}{ccrrrrrr}
\hline \multirow{2}{*}{$\begin{array}{c}\text { Kenar } \\
\text { oranı } \\
\text { (b/a) }\end{array}$} & YöNTEM & \multicolumn{7}{c}{ LT1 } & LT2 & LT3 & LT4 & LT5 & LT6 \\
\cline { 3 - 8 } & & \multicolumn{1}{c}{$\mathrm{N}_{\mathrm{kr}}$} & \multicolumn{1}{c}{$\mathrm{N}_{\mathrm{kr}}$} & \multicolumn{1}{c}{$\mathrm{N}_{\mathrm{kr}}$} & \multicolumn{1}{c}{$\mathrm{N}_{\mathrm{kr}}$} & $\mathrm{N}_{\mathrm{kr}}$ & $\mathrm{N}_{\mathrm{kr}}$ \\
\hline \multirow{2}{*}{1.00} & Rayleigh-Ritz & 174309 & 160364 & 198665 & 198665 & 160364 & 174309 \\
& SEY(ANSYS) & 165240 & 147060 & 194881 & 194846 & 146759 & 164923 \\
\multirow{2}{*}{1.20} & Rayleigh-Ritz & 131725 & 119979 & 143385 & 138753 & 110096 & 117302 \\
& SEY(ANSYS) & 125663 & 111092 & 140813 & 136169 & 100499 & 110667 \\
1.40 & Rayleigh-Ritz & 108126 & 98296 & 112655 & 106040 & 84237 & 87566 \\
& SEY(ANSYS) & 103802 & 91979 & 110797 & 104178 & 77113 & 82603 \\
1.60 & Rayleigh-Ritz & 93645 & 85294 & 93761 & 86188 & 69275 & 70160 \\
& SEY(ANSYS) & 90408 & 80583 & 92355 & 84782 & 63791 & 66298 \\
\multirow{2}{*}{1.80} & Rayleigh-Ritz & 84099 & 76866 & 81290 & 73210 & 59864 & 59106 \\
& SEY(ANSYS) & 81582 & 73220 & 80187 & 72112 & 55521 & 56013 \\
2.00 & Rayleigh-Ritz & 77463 & 71083 & 72612 & 64247 & 53565 & 51651 \\
& SEY(ANSYS) & 75446 & 68174 & 71723 & 63365 & 50046 & 49117 \\
\hline
\end{tabular}


Tablo 7. devamı Kritik Burkulma Yükü $\mathrm{N}_{\mathrm{kr}}(\mathrm{N} / \mathrm{m})$, kısa kenar " $\mathrm{x}$ ” ekseninde

\begin{tabular}{|c|c|c|c|c|c|c|c|}
\hline \multirow{3}{*}{$\begin{array}{c}\text { Kenar } \\
\text { oranı } \\
(b / a)\end{array}$} & \multirow{3}{*}{ YÖNTEM } & \multicolumn{6}{|c|}{ Laminasyon Tipi } \\
\hline & & LT7 & LT8 & LT9 & LT10 & LT11 & LT12 \\
\hline & & $\mathrm{N}_{\mathrm{kr}}$ & $\mathrm{N}_{\mathrm{kr}}$ & $\mathrm{N}_{\mathrm{kr}}$ & $\mathrm{N}_{\mathrm{kr}}$ & $\mathrm{N}_{\mathrm{kr}}$ & $\mathrm{N}_{\mathrm{kr}}$ \\
\hline \multirow[t]{2}{*}{1.00} & Rayleigh-Ritz & 157781 & 146448 & 157781 & 146448 & 133744 & 133744 \\
\hline & SEY(ANSYS) & 155872 & 143071 & 155872 & 143071 & 133201 & 133201 \\
\hline \multirow[t]{2}{*}{1.20} & Rayleigh-Ritz & 127509 & 117741 & 127509 & 117741 & 104463 & 104463 \\
\hline & SEY(ANSYS) & 126160 & 115437 & 126160 & 115437 & 104044 & 104044 \\
\hline \multirow[t]{2}{*}{1.40} & Rayleigh-Ritz & 110808 & 102521 & 110808 & 102521 & 90175 & 90175 \\
\hline & SEY(ANSYS) & 109802 & 100847 & 109802 & 100847 & 89846 & 89846 \\
\hline \multirow[t]{2}{*}{1.60} & Rayleigh-Ritz & 100591 & 93469 & 100591 & 93469 & 82255 & 82255 \\
\hline & SEY(ANSYS) & 99805 & 92192 & 99805 & 92192 & 81987 & 81987 \\
\hline \multirow[t]{2}{*}{1.80} & Rayleigh-Ritz & 93866 & 87634 & 93866 & 87634 & 77439 & 77439 \\
\hline & SEY(ANSYS) & 93229 & 86622 & 93229 & 86622 & 77214 & 77214 \\
\hline \multirow[t]{2}{*}{2.00} & Rayleigh-Ritz & 89196 & 83644 & 89196 & 83644 & 74300 & 74300 \\
\hline & SEY(ANSYS) & 88664 & 82817 & 88664 & 82817 & 74105 & 74105 \\
\hline \multirow{3}{*}{$\begin{array}{l}\text { Kenar } \\
\text { oranı } \\
(b / a)\end{array}$} & \multicolumn{7}{|c|}{ Laminasyon Tipi } \\
\hline & \multirow{2}{*}{ YÖNTEM } & LT13 & LT14 & LT15 & LT16 & LT17 & LT18 \\
\hline & & $\mathrm{N}_{\mathrm{kr}}$ & $\mathrm{N}_{\mathrm{kr}}$ & $\mathrm{N}_{\mathrm{kr}}$ & $\mathrm{N}_{\mathrm{kr}}$ & $\mathrm{N}_{\mathrm{kr}}$ & $\mathrm{N}_{\mathrm{kr}}$ \\
\hline \multirow[t]{2}{*}{1.00} & Rayleigh-Ritz & 198665 & 198665 & 174309 & 160364 & 174309 & 160364 \\
\hline & SEY(ANSYS) & 194881 & 194846 & 165240 & 147060 & 164923 & 146759 \\
\hline \multirow[t]{2}{*}{1.20} & Rayleigh-Ritz & 143385 & 138753 & 131725 & 119979 & 117302 & 110096 \\
\hline & SEY(ANSYS) & 140813 & 136169 & 125663 & 111092 & 110667 & 100499 \\
\hline \multirow[t]{2}{*}{1.40} & Rayleigh-Ritz & 112655 & 106040 & 108126 & 98296 & 87566 & 84237 \\
\hline & SEY(ANSYS) & 110797 & 104178 & 103802 & 91979 & 82603 & 77113 \\
\hline \multirow[t]{2}{*}{1.60} & Rayleigh-Ritz & 93761 & 86188 & 93645 & 85294 & 70160 & 69275 \\
\hline & SEY(ANSYS) & 92355 & 84782 & 90408 & 80583 & 66298 & 63791 \\
\hline \multirow[t]{2}{*}{1.80} & Rayleigh-Ritz & 81290 & 73210 & 84099 & 76866 & 59106 & 59864 \\
\hline & SEY(ANSYS) & 80187 & 72112 & 81582 & 73220 & 56013 & 55521 \\
\hline \multirow[t]{2}{*}{2.00} & Rayleigh-Ritz & 72612 & 64247 & 77463 & 71083 & 51651 & 53565 \\
\hline & SEY(ANSYS) & 71723 & 63365 & 75446 & 68174 & 49117 & 50046 \\
\hline \multirow{3}{*}{$\begin{array}{l}\text { Kenar } \\
\text { oranı } \\
\text { (b/a) }\end{array}$} & \multirow{3}{*}{ YÖNTEM } & \multicolumn{6}{|c|}{ Laminasyon Tipi } \\
\hline & & LT19 & LT20 & LT21 & LT22 & LT23 & LT24 \\
\hline & & $\mathrm{N}_{\mathrm{kr}}$ & $\mathrm{N}_{\mathrm{kr}}$ & $\mathrm{N}_{\mathrm{kr}}$ & $\mathrm{N}_{\mathrm{kr}}$ & $\mathrm{N}_{\mathrm{kr}}$ & $\mathrm{N}_{\mathrm{kr}}$ \\
\hline \multirow[t]{2}{*}{1.00} & Rayleigh-Ritz & 146448 & 157781 & 133744 & 133744 & 157781 & 146448 \\
\hline & SEY(ANSYS) & 142903 & 155762 & 133193 & 133193 & 155762 & 142903 \\
\hline \multirow[t]{2}{*}{1.20} & Rayleigh-Ritz & 94287 & 99857 & 90750 & 90750 & 99857 & 94287 \\
\hline & SEY(ANSYS) & 91803 & 98489 & 90368 & 90368 & 98489 & 91803 \\
\hline 1.40 & Rayleigh-Ritz & 69094 & 71333 & 70595 & 70595 & 71333 & 69094 \\
\hline & SEY(ANSYS) & 67250 & 70343 & 70323 & 70323 & 70343 & 67250 \\
\hline 1.60 & Rayleigh-Ritz & 55284 & 55408 & 59836 & 59836 & 55408 & 55284 \\
\hline & SEY(ANSYS) & 53860 & 54658 & 59634 & 59634 & 54658 & 53860 \\
\hline 1.80 & Rayleigh-Ritz & 46982 & 45674 & 53516 & 53516 & 45674 & 46982 \\
\hline & SEY(ANSYS) & 45849 & 45085 & 53361 & 53361 & 45085 & 45849 \\
\hline 2.00 & Rayleigh-Ritz & 41630 & 39305 & 49522 & 49522 & 39305 & 41630 \\
\hline & SEY(ANSYS) & 40707 & 38831 & 49398 & 49398 & 38831 & 40707 \\
\hline
\end{tabular}




\subsection{Boyutsuz sonuçlar}

Önceki bölümdeki sayısal analizlerde, Rayleigh-Ritz Yöntemi'yle bulunan sonuçlar, SEY (ANSYS) ile bulunanlarla karşılaştırılıp yakın sonuçlar elde edilmiş, R-R Yöntemi'nin güvenilirliği görülmüștür. $\mathrm{Bu}$ bölümde RayleighRitz Yöntemi ile T300-934 kodlu karbon/epoksi malzeme için elde edilen boyutsuz sonuçlar sunulmuştur (Tablo 8-9). Burada boyutsuz kritik burkulma yükü; plağın kısa kenarının, kalınlığının ve elastisite modülünün fonksiyonu olarak verilmiştir.
$N_{x}$ eksenel basınç yükü, " $\mathrm{x}$ " eksenine paralel olduğunda $\left(\mathrm{N}_{\mathrm{kr}}\right)$; kısa kenar " $\mathrm{y}$ " ekseninde olduğu durum için boyutsuz kritik burkulma yükü $N_{0}^{*}=N_{k r} \frac{b^{2}}{t^{3} E_{22} 10}$

kısa kenar " $\mathrm{x}$ " ekseninde olduğu durum için ise $N_{0}^{*}=N_{k r} \frac{a^{2}}{t^{3} E_{22} 10}$ olarak verilmiştir.

Tablo 8. Boyutsuz Kritik Burkulma Yükü ( $\left.N_{0}^{*}\right)$, kısa kenar "y" ekseninde

\begin{tabular}{|c|c|c|c|c|c|c|}
\hline \multirow{2}{*}{$\begin{array}{c}\text { Laminasyon } \\
\text { Tipi }\end{array}$} & \multicolumn{6}{|c|}{ Kenar Oranları (a/b) } \\
\hline & 1 & 1.2 & 1.4 & 1.6 & 1.8 & 2 \\
\hline LT1 & 9032,2 & 8751,9 & 8892,6 & 9306,5 & 9922,3 & 10705,3 \\
\hline LT2 & 8309,3 & 8214,6 & 8554,1 & 9189,7 & 10049,3 & 11101,7 \\
\hline LT3 & 10293,5 & 10352,6 & 10769,3 & 11432,6 & 12290,6 & 13315,7 \\
\hline LT4 & 10293,5 & 10699,7 & 11440,8 & 12437,3 & 13646,4 & 15051,6 \\
\hline LT5 & 8309,3 & 8952,0 & 9982,1 & 11314,2 & 12904,2 & 14731,4 \\
\hline LT6 & 9032,2 & 9827,9 & 10982,1 & 12421,6 & 14118,8 & 16056,7 \\
\hline LT7 & 8175,5 & 7450,9 & 7245,8 & 7350,6 & 7667,8 & 8146,5 \\
\hline LT8 & 7588,1 & 7035,0 & 7018,3 & 7333,0 & 7887,5 & 8627,8 \\
\hline LT9 & 8175,5 & 7450,9 & 7245,8 & 7350,6 & 7667,8 & 8146,5 \\
\hline LT10 & 7588,1 & 7035,0 & 7018,3 & 7333,0 & 7887,5 & 8627,8 \\
\hline LT11 & 6930,4 & 6771,4 & 7170,5 & 7937,2 & 8984,2 & 10263,7 \\
\hline LT12 & 6930,4 & 6771,4 & 7170,5 & 7937,2 & 8984,2 & 10263,7 \\
\hline LT13 & 10293,5 & 10352,6 & 10769,3 & 11432,6 & 12290,6 & 13315,7 \\
\hline LT14 & 10293,5 & 10699,7 & 11440,8 & 12437,3 & 13646,4 & 15051,6 \\
\hline LT15 & 9032,2 & 8751,9 & 8892,6 & 9306,5 & 9922,3 & 10705,3 \\
\hline LT16 & 8309,3 & 8214,6 & 8554,1 & 9189,7 & 10049,3 & 11101,7 \\
\hline LT17 & 9032,2 & 9827,9 & 10982,1 & 12421,6 & 14118,8 & 16056,7 \\
\hline LT18 & 8309,3 & 8952,0 & 9982,1 & 11314,2 & 12904,2 & 14731,4 \\
\hline LT19 & 7588,1 & 8784,7 & 10411,8 & 12398,1 & 14711,4 & 17336,3 \\
\hline LT20 & 8175,5 & 9513,5 & 11254,3 & 13342,3 & 15757,8 & 18486,0 \\
\hline LT21 & 6930,4 & 7794,2 & 9158,8 & 10910,4 & 13000,3 & 15401,5 \\
\hline LT22 & 6930,4 & 7794,2 & 9158,8 & 10910,4 & 13000,3 & 15401,5 \\
\hline LT23 & 8175,5 & 9513,5 & 11254,3 & 13342,3 & 15757,8 & 18486,0 \\
\hline LT24 & 7588,1 & 8784,7 & 10411,8 & 12398,1 & 14711,4 & 17336,3 \\
\hline
\end{tabular}


Tablo 9. Boyutsuz Kritik Burkulma Yükü ( $\left.N_{0}^{*}\right)$, kısa kenar “y” ekseninde

$$
\left(N_{0}^{*}=N_{k r} \frac{a^{2}}{t^{3} E_{22} 10}\right)
$$

\begin{tabular}{ccccccc}
\hline Laminasyon & \multicolumn{5}{c}{ Kenar Oranlarl (b/a) } \\
\cline { 2 - 7 } Tipi & $\mathbf{1}$ & $\mathbf{1 . 2}$ & $\mathbf{1 . 4}$ & $\mathbf{1 . 6}$ & $\mathbf{1 . 8}$ & $\mathbf{2}$ \\
\hline LT1 & 9032,2 & 6825,7 & 5602,6 & 4852,1 & 4357,5 & 4013,7 \\
LT2 & 8309,3 & 6217,1 & 5093,2 & 4419,4 & 3982,8 & 3683,1 \\
LT3 & 10293,5 & 7429,0 & 5837,4 & 4858,1 & 4212,3 & 3762,4 \\
LT4 & 10293,5 & 7189,9 & 5494,1 & 4465,6 & 3793,1 & 3328,8 \\
LT5 & 8309,3 & 5704,1 & 4364,5 & 3589,5 & 3101,6 & 2775,3 \\
LT6 & 9032,2 & 6078,4 & 4537,2 & 3635,2 & 3062,8 & 2676,4 \\
LT7 & 8175,5 & 6607,2 & 5741,9 & 5213,2 & 4863,8 & 4621,6 \\
LT8 & 7588,1 & 6101,2 & 5312,0 & 4842,9 & 4541,1 & 4333,8 \\
LT9 & 8175,5 & 6607,2 & 5741,9 & 5213,2 & 4863,8 & 4621,6 \\
LT10 & 7588,1 & 6101,2 & 5312,0 & 4842,9 & 4541,1 & 4333,8 \\
LT11 & 6930,4 & 5413,1 & 4672,3 & 4261,9 & 4012,7 & 3849,9 \\
LT12 & 6930,4 & 5413,1 & 4672,3 & 4261,9 & 4012,7 & 3849,9 \\
LT13 & 10293,5 & 7429,0 & 5837,4 & 4858,1 & 4212,3 & 3762,4 \\
LT14 & 10293,5 & 7189,9 & 5494,1 & 4465,6 & 3793,1 & 3328,8 \\
LT15 & 9032,2 & 6825,7 & 5602,6 & 4852,1 & 4357,5 & 4013,7 \\
LT16 & 8309,3 & 6217,1 & 5093,2 & 4419,4 & 3982,8 & 3683,1 \\
LT17 & 9032,2 & 6078,4 & 4537,2 & 3635,2 & 3062,8 & 2676,4 \\
LT18 & 8309,3 & 5704,1 & 4364,5 & 3589,5 & 3101,6 & 2775,3 \\
LT19 & 7588,1 & 4885,1 & 3580,1 & 2864,5 & 2434,6 & 2157,1 \\
LT20 & 8175,5 & 5174,5 & 3696,1 & 2871,0 & 2366,7 & 2036,4 \\
LT21 & 6930,4 & 4702,0 & 3658,0 & 3100,5 & 2772,9 & 2565,9 \\
LT22 & 6930,4 & 4702,0 & 3658,0 & 3100,5 & 2772,9 & 2565,9 \\
LT23 & 8175,5 & 5174,5 & 3696,1 & 2871,0 & 2366,7 & 2036,4 \\
LT24 & 7588,1 & 4885,1 & 3580,1 & 2864,5 & 2434,6 & 2157,1 \\
\hline
\end{tabular}

\section{Tartışma ve Sonuç}

En büyük kritik burkulma yükü $\mathrm{a} / \mathrm{b}=2$ için LT23 kodlu plakta $356785 \mathrm{~N} / \mathrm{m}$ olarak görülmektedir. $\mathrm{Bu}$ durum boyuna yapı sistemine karșllk gelmektedir. Enine sistemde kritik burkulma yükü değerleri düşmektedir. Burada boyuna yapı sisteminin kullanımı burkulmaya daha dayanıklı bir yapı elde edilmesi anlamına gelmektedir. $\mathrm{Bu}$ durum çelik gibi izotrop malzemeler açısından da karşılașllan bir durum olmakta ve sonuçlar bu açıdan da uyumlu bulunmaktadır.

Önceki bölümde simetrik katmanlı ince dikdörtgen kompozit plakların boyutsuz kritik burkulma yükü $\left(N_{0}^{*}\right)$ plak kısa kenarına, plak kalınlığına ve elastisite modülüne bağlı olarak 
verilmiştir. Kısa kenar y ekseninde olduğu durumda

$N_{0}^{*}=N_{k r} \frac{b^{2}}{t^{3} E_{22} 10}$ olarak, x ekseninde olduğu durumda ise

$N_{0}^{*}=N_{k r} \frac{a^{2}}{t^{3} E_{22} 10}$ olarak bulunmuştur.

$\mathrm{Bu}$ iki boyutsuz ifade Reddy'nin çalışmasında da sf:421-422'de [24] benzer biçimde gösterilmiştir. $\mathrm{Bu}$ benzerlik de hesaplamaların sağlamasının yapıldığını göstermektedir.

Kompozit gemilerin yapımında; malzeme seçimi, destek elemanlarının

\section{Kaynakça}

[1] Reuben, R.L. 1994. Materials in Marine Technology. SpringerVerlag, London Limited, UK.

[2] Shenoi, R.A., Wellicome, J.F. 1993. Composite Materials in Maritime Structures, Volume-I (Fundamental Aspects), Cambridge University Pres, NY.

[3] Shenoi, R.A., Wellicome, J.F. 1993. Composite Materials in Maritime Structures, Volume-II (Practical Considerations), Cambridge University Pres, NY.

[4] Mouritz, A.P., Gellert, E., Burchill, P., Challis K., 2001. Review of Advanced Composite Structures for Naval Ships and Submarines, Composite Structures, Cilt. 53, s..21-41.DOI:10.1016/S02638223(00)00175-6

[5] Savcı, M., 1987. Gemi Yapısında Levhalar ve Silindirik Kabuklar, İ.T.Ü. Gemi İnş. ve Deniz Bil. Fak, İstanbul.

[6] Lekhnitskii, S.G.1968. Anisotropic Plates, Gordon and Breach, NewYork. yerleşimine bağlı olarak enine veya boyuna sistemdeki yapı, farklı kenar oranları, katmanların farklı açılarda sıralanması ve geminin farklı yerlerindeki farklı uygulamaların olması gibi neredeyse sonsuz sayıda seçenek söz konusu olmaktadır. Kompozit gemilerin yapısal ön tasarımında, bu çalışmadakine benzer olarak Rayleigh-Ritz Yöntemi ile hızlı biçimde boyutsuz tabloların oluşturulup, uygun seçeneklerin belirlenmesiyle, üretimdeki zaman, malzeme, deney ve işgücünden tasarruf edilmesi öngörülmüştür.

[7] Aran, A., 1990. Elyaf Takviyeli Karma Malzemeler, I.T.Ü. Kütüphanesi Sayı:1420, Gümüşsuyu, İstanbul.

[8] Powell, P.C., 1994. Engineering with fibre-polymer laminates, Chapman \& Hall, London, UK.

[9] Mallick. P. K., 1997. Composites engineering handbook, Marcel Dekker Inc., NY.

[10] ASM Handbook, 2001. Volume 21, Composites, ASM International.

[11] Harper, C.A., 2002. Handbook of plastics, elastomers, and composites, McGraw-Hill, NY.

[12] Ambartsumyan, S.A, 1970. Theory of Anisotropic Plates, Technomic Publishing, Co., Wesport Conn.

[13] Baharlou, B., Leissa A.W., 1987. Vibration and Buckling of Generally Laminated Composite Plates with Arbitrary Edge conditions, Int. J. Mech. Sci. Vol. 29, No. 8, pp. 545-555.DOI: 10.1016/0020-7403(87)90026-9

[14] Lakshminarayana, L., Kumar, Krishna Mohana Rao G., 2012. Buckling analysis of quasiisotropic symmetrically 
laminated rectangular composite plates with an elliptical/circular cutout subjected to linearly varying in-plane loading using FEM, International Journal of Mechanics, Issue 1, Volume 6.

[15] Hu, H., Badir, A., Abatan, A., 2003. Buckling behavior of a graphite/epoxy composite plate under parabolic variation of axial loads, Int. J. Mech. Sci. 45, 11351147.DOI:10.1016/j.ijmecsci.200 3.08 .003

[16] Darvizeh, M., Darvizeh, A., Ansari, R., Sharma, C.B., 2004. Buckling analysis of generally laminated composite plates (generalized differential quadrature rules versus Rayleigh-Ritz method), Composite Structures 63, 6974.DOI: $\quad$ 10.1016/S02638223(03)00133-8

[17] Aydoğdu, M., 2009. A new shear deformation theory for laminated composite plates, Composite Structures 89, 94-101.DOI: 10.1016/j.compstruct.2008.07.00 8

[18] Felix, D.H., Bambill, D.V.,Rossit, C.A., 2011. A note on buckling and vibration of clamped orthotropic plates under in-plane loads. Struct. Eng. Mech., 39 (1), 115123,DOI:10.12989/sem.2011.39. 1.115

[19] Aydoğdu, M., Tımarcl, T., 2004. Düzlem-içi yüklenmiş basit destekli simetrik katmanlı dikdörtgen kompozit ince plakların burkulma ve titreșimi, Trakya Univ J Sci, 5(2): 167-177.

[20] Aydoğdu, M., Aksencer, T., 2017. Buckling of Cross-ply Composite Plates with Linearly Varying Inplane Loads, 3 January,
[21] Kumar, Y., 2017. The RayleighRitz method for linear dynamic, static and buckling behavior of beams, shells and plates: A literature review, Journal of Vibration and Control, 1-23

[22] Noor, A.K., Burton W.S., 1989. Assesment of shear deformation theories for multilayered composite plates, Appl Mech Rev. 42 (1),DOI:10.1115/1.3152418

[23] Noor, A.K., Burton W.S., 1990. Assesment of computational model for multilayered composite plates, Appl Mech Rev., 43 (4): 67-97.DOI: $\quad$ 10.1016/02638223(90)90050-0

[24] Mallikarjuna, Kant, T., 1993. A critical review and some results of recently developed refined theories of fiber-reinforced laminated composites and sandwiches, $\quad$ Composite Structures, 23 293312.DOI:10.1016/02638223(93)90230-N

[25] Altunsaray, E., Bayer, İ., 2004. Buckling of symmetrically laminated quasi-isotropic thin rectangular plates, Steel Compos. Struct., Int. J.,17(3),305-320. DOI: http://dx.doi.org/10.12989/scs.2 014.17.3.305

[26] Tsai, S.W., 1988. Composites design, 4th Edition, Think Composites.

[27] Reddy, J.N, 2004. Mechanics of Laminated Composite Plates and Shells: Theory and Analysis, Second edition, CRC Pres.

[28] Ashton, J.E., Whitney, J.M., 1970, Theory of Laminated Plates, Technomic Publication, USA.

[29] ANSYS 17 Academic, 2017. 